\title{
CONHECIMENTO TRADICIONAL E PRÁTICAS AGROECOLÓGICAS COMO FORMA DE RESISTÊNCIA DA RURALIDADE NO PLANALTO SUL DE SANTA CATARINA
}

\author{
Patrine Souza ${ }^{1}$ \\ João Fert Neto ${ }^{2}$ \\ Joseane Madruga ${ }^{3}$ \\ Patricia Fernandes ${ }^{4}$ \\ Silvia Danieli Werter ${ }^{5}$
}

\section{RESUMO}

Este trabalho está focado no estudo de um grupo de mulheres agricultoras no município de Otacílio Costa/SC, caracterizadas pela reprodução da sua ruralidade num cenário onde predominam atividades de reflorestamento com Pinus sp. Este grupo tem as suas estratégias voltadas para práticas agroecológicas e a realização de feiras de venda direta. Utilizou-se a abordagem teórica-metodológica de Pierre Bourdieu, através dos conceitos de habitus, capitais e de reprodução social. Para a coleta de dados, utilizou-se questionários semiestruturados, observação participante e impressões através de diálogos e acompanhamento de atividades. Observou-se uma condição de resistência decorrente de estratégias de recuperação de conhecimentos tradicionais, a partir de práticas culturais, numa perspectiva agroecológica. Essa resistência assume funcionalidade à manutenção da ruralidade, pois proporciona identidade sociocultural de agricultor agroecológico, acesso às políticas públicas e capital simbólico diante da comunidade.

Palavras-chave: capital simbólico, identidade sociocultural, mulheres agricultoras.

\section{TRADITIONAL KNOWLEDGE AND AGROECOLOGICAL PRACTICES AS A WAY OF RURALITY RESISTANCE IN SANTA CATARINA SOUTH HIGHLANDS}

\footnotetext{
ABSTRACT

This work is focused on the study of a group of women farmers in the municipality of Otacílio Costa/SC, characterized by the reproduction of its rurality in a setting dominated by the reforestation with Pinus. This group has its strategies for agro-

${ }^{1}$ Graduada em Agronomia (CAV-UDESC). Mestranda em Desenvolvimento Rural (UFRGS). Email: souzapatrine@gmail.com

${ }^{2}$ Graduado em Engenharia Florestal (UFSM). Mestrado em Sociologia (UFRGS). Doutorado Interdisciplinar em Ciência Humanas:Sociedade e Meio Ambiente (UFSC). Professor Associado da Universidade do Estado de Santa Catarina (UDESC). Email: joao.fert@udesc.br

${ }^{3}$ Graduada em Agronomia (CAV-UDESC). Email: joseane_madruga@hotmail.com

${ }^{4}$ Graduada em Agronomia (UFPR). Mestrado em Desenvolvimento Rural (UFRGS). Doutorado em Produção

Vegetal (CAV-UDESC). Professora Adjunta da Universidade Tecnológica Federal do Paraná (UTFPR).

Email: patriciaf@utfpr.edu.br

${ }^{5}$ Graduanda em Agronomia (CAV-UDESC). Email: silvia.werter@hotmail.com
} 
ecological practices and the realization of direct sales fairs. We used the theoreticalmethodological approach of Pierre Bourdieu, through the concepts of habitus, capital and social reproduction. To collect data, we used semi-structured questionnaires, participant observation and impressions through dialogue and follow-up activities. It was observed that this resistance occurs because of traditional knowledge recovery strategies, from cultural practices through agro-ecological perspective, assuming a feature to the maintenance of rural life as it provides sociocultural identity of agroecological farmers, access to public policy and symbolic capital against the community.

Keywords: socio-cultural identity, symbolic capital, women farmers.

\section{INTRODUÇÃO}

Num sentido histórico, a perda de ruralidade no Brasil ocorreu em congruência com o processo de modernização da agricultura (GRAZIANO DA SILVA, 1981), que inviabilizou a agricultura familiar tradicional e as suas práticas agrícolas correspondentes, como a coivara, o pousio, a mudança de mercado e, mais recentemente, o êxodo seletivo por parte dos jovens e de mulheres do meio rural.

Conforme Abramovay (1998), considerando a estrutura do mercado agrícola do Brasil, dominado por grandes proprietários de terra e multinacionais, as formas de produção e comércio pressionam o agricultor familiar a procurar outras formas de trabalho a fim de garantir sua sobrevivência, mudando para as cidades ou trabalhando de forma assalariada no campo.

Esse processo, conhecido como modernização conservadora da agricultura (MARTINE et al., 1985; GRAZIANO DA SILVA, 1981), historicamente tem provocado um declínio da agricultura familiar e uma perda da sua ruralidade, com esvaziamento das áreas rurais, envelhecimento da população e descontinuidade nas propriedades familiares, com a evasão de jovens para os centros urbanos. Como bem apontou Williams (1989), isto pode levar ao desaparecimento do campo e tudo que ele significa em termos culturais e sociais.

O processo de perda da ruralidade continua com a evasão da população jovem e feminina, atraídos pela busca de escolaridade e empregos no meio urbano. No entanto, isto não é absoluto, podendo haver contra tendências. Como aponta Graziano da Silva (2002), a queda da população rural brasileira observada na década de 80 reverteu-se, passando a crescer a uma taxa de 0,9\% a.a. no decorrer dos anos 90. De acordo com o autor, o que manteve as pessoas no campo brasileiro não foram as atividades agropecuárias, mas sim as ocupações não-agrícolas e a ampliação da cobertura da Previdência Social para as áreas rurais.

O Planalto Sul De Santa Catarina, região de estudo do presente trabalho, seguiu a tendência geral de regiões onde havia predominância da agricultura familiar no seu processo histórico de formação. É considerada uma das regiões mais pobres do estado (SANTA CATARINA, 2003) e sofreu um intenso êxodo rural nas décadas de 60 e 70 do século XX. As causas apontadas são o fim de um processo econômico extrativo das florestas de araucária, chamado de "Ciclo da Madeira", e o consequente fechamento das serrarias, aliado à falta de opções de ocupação no meio rural da região (FERT NETO, 1993).

Concomitante ao fim da exploração da madeira, a região se modernizou a partir de empreendimentos agropecuários como grandes empresas reflorestadoras e, mais recentemente, a agricultura intensiva de grãos (GOULARTI FILHO, 2002). 
Soma-se a tais fatos o investimento urbano de compra de terras no meio rural e a manutenção das grandes propriedades muitas vezes apenas para lazer. Isto contribuiu para diminuir o espaço da agricultura e do campesinato na região do Planalto Sul De Santa Catarina.

Um forte atrativo para o meio urbano tem sido o aumento das exigências sociais (saúde, educação, serviços, segurança) e a carência destas condições no meio rural, ou nas pequenas cidades do interior. A chamada desterritorialização (HAESBAERT, 2005) dos agricultores familiares ocasiona uma mudança nos processos sociais, ambientais e econômicos existentes no meio rural, que podem refletir impactos negativos sobre as cidades, principalmente naquelas de pequeno e médio porte que possuem uma grande relação econômica com a agricultura.

Esse processo de urbanização tem acarretado não somente uma perda em relação ao espaço rural, mas também uma perda de ruralidade em termos culturais, na medida em que as bases físicas de manutenção da vida cultural e dos valores sociais vão se perdendo (BLOEMER, 2000). Observando os novos moradores das pequenas cidades e na periferia das médias, verifica-se tratar-se de um processo incompleto de urbanização, gerador de uma situação de exclusão social, suburbanização, marginalidade e estranhamento, que dificulta a socialização dessa nova população no meio urbano ou ocorre de forma precária.

Entretanto, mesmo diante deste cenário de desaparecimento da ruralidade, podem ser encontrados focos de persistência de diferentes ruralidades, que se moldam aos novos contextos, através de práticas culturais e socioeconômicas que permitem essa permanência. Pode-se afirmar que, mesmo nas transformações profundas por que passa a modernidade, o rural não se 'perde', ao contrário, pode reafirmar a sua importância e particularidade.

Neste estudo, entende-se que as diferentes regiões brasileiras sofreram - e em seguida estabilizaram - o êxodo rural pelas mais diversas razões, dentre elas as citadas por Graziano, mas também por meio da ressurgência de diferentes ruralidades, considerando as infinitas possibilidades e maneiras de existir/reproduzir o rural a partir do etnoconhecimento e das mais diversas formas de resistência social e modos de vida encontrados no país.

Neste contexto, o trabalho está focado no estudo de um grupo de mulheres agricultoras no município de Otacílio Costa/SC, caracterizadas pela reprodução da sua ruralidade num cenário onde predominam atividades comerciais de reflorestamento. Este grupo tem as suas estratégias voltadas para práticas agroecológicas e a realização de feiras de venda direta. O objetivo do estudo foi identificar as estratégias de resistência e a permanência deste grupo e como essas estratégias contribuem para a reprodução da sua ruralidade.

\section{RURALIDADE, GÊNERO E AGROECOLOGIA}

Conforme Durán (1998), o termo ruralidade pode ser entendido como um modo de vida, como uma sociabilidade que é pertinente ao mundo rural, com relações internas específicas e diversas do modo de viver urbano. Considera a ruralidade uma palavra polissêmica, que sugere multiplicidade de sentidos quando mencionada. Ruralidade é uma construção social contextualizada, tendo caráter reflexivo, ou seja, é o resultado das ações de indivíduos que possuem a capacidade de interiorizar, discutir e refletir sobre a situação e necessidade sociocultural apresentada em cada tempo e espaço.

Karam (2002) considera a ruralidade como uma construção social no conjunto societário. A ruralidade deve ser conhecida nos seus termos e não referida à cidade, como sua periferia espacial precária, dela dependendo política, econômica 
e socialmente. Entretanto, a relação entre rural e urbano no âmbito da modernidade tem sido sistematicamente tensionada por um tipo de concepção que valora positivamente o urbano como lócus privilegiado de realização do que é moderno e do que é o progresso, e negativamente o rural como lócus do que é tradicional e do que é atrasado.

Neste sentido, Williams (1989) chama a atenção para o quão poderosas são as palavras "campo" e "cidade", as quais historicamente foram associadas pelas comunidades humanas à imagens e atitudes emocionais. $O$ campo esteve associado a uma forma natural de vida - de paz, inocência e virtudes simples; e a cidade à ideia de centro de realizações - de saber, de comunicações, luz. Mas também a associações negativas: a cidade como lugar de barulho, mundanidade, ambição; o campo como lugar de atraso, ignorância, limitação. Todavia, segue o autor, a realidade histórica é "surpreendentemente variada", o campo pode englobar, desde caçadores e pastores até as modernas empresas agroindustriais; a cidade, como a conhecemos, hoje, nas suas funções e configurações, pouco tem a ver com a cidade antiga ou medieval, a não ser o nome. Também há uma complexa variedade de formas intermediárias, entre o campo e a cidade. Além disto, as representações do campo e do passado, ao qual são associadas, têm significados diferentes em épocas diferentes, e colocam em questão valores diversos.

Mesmo que o meio rural esteja integrado à sociedade e ainda que possa ser dotado de paridade social, permanece sendo visto como o lócus do atrasado, do tradicional. Por outro lado, a modernidade continua a se surpreender com a manutenção, a permanência e a capacidade de transformação e de mudanças que ocorrem no espaço rural.

Henri Lefebvre (1986), na década de 50, chamava a atenção dos sociólogos dizendo que as questões do mundo rural são muito mais diversas e múltiplas do que parecem. Considerava que a sociologia rural, que se debruçava sobre o mundo rural para estudá-lo, tinha uma dívida para com a ruralidade, uma vez que os estudos sociológicos "passaram do estudo dos povos 'primitivos' ao estudo dos meios urbanos e industriais, saltando por cima, por assim dizer, dessa realidade tão vasta no tempo e no espaço".

De uma maneira recorrente na sociologia rural, duas perspectivas se confrontam: aquela que encontra cada vez mais indícios do desaparecimento da ruralidade e aquela que observa os mesmos processos macrossociais, mas considera que o mundo rural não se reduz à homogeneização da sociedade contemporânea, pois há particularidades de modos de vida que permitem que sejam observadas permanências, reconstruções, emergências de processos sociais que dão especificidade às formas de vida rural.

Há uma retomada do antigo tema da sociologia rural que é o continuum rural urbano, em que processos rurais contemporâneos são uma continuidade espacial dos processos urbanos, embora também possa se observar uma certa permanência de aspectos simbólicos do rural no urbano.

Wanderley (2000) afirma que "as diferenças espaciais e sociais das sociedades modernas apontam não para o fim do mundo rural; mas para a emergência de uma nova ruralidade". Assim, nas transformações profundas por que passa a modernidade, o rural não se 'perde', ao contrário, reafirma sua importância e particularidade. Nesse contexto, observa-se o uso de algumas designações, tais como: a emergência de uma nova ruralidade, o renascimento do rural, a ruralidade contemporânea, a valorização do meio rural, a ressignificação do rural. Desta maneira, as reflexões sobre a ruralidade na atualidade exigem o reconhecimento do rural, tanto nas suas relações com o urbano, como nas suas relações internas e específicas. 
Desde muito tempo, alguns atores sociais vêm buscando estabelecer estilos de agricultura menos agressivos ao meio ambiente, capazes de proteger os recursos naturais, tentando fugir do estilo convencional de agricultura que passou a ser hegemônico no início do século XX. Vários países passaram a seguir estas agriculturas alternativas, com diferentes denominações: orgânica, biológica, ecológica, natural, biodinâmica, permacultura, entre outras. Cada uma delas seguindo determinadas filosofias, princípios tecnológicos e regras. Contudo, na maioria das vezes, tais alternativas não conseguiram dar as respostas para os problemas socioambientais que foram se acumulando como resultado do modelo convencional de desenvolvimento e de agricultura que passaram a predominar, particularmente, depois da II Guerra Mundial com a chamada "Revolução Verde" (CAPORAL; COSTABEBER, 2004).

No Brasil, esse modelo foi implantado a partir do que se chamou de modernização conservadora da agricultura, num período de ditadura militar. Estas condições estimularam o ressurgimento de alguns movimentos sociais no campo no início dos anos 80, como: Pastoral da Terra, Movimento dos Trabalhadores Sem Terra, Movimento das Mulheres Trabalhadoras Rurais, Movimento dos Atingidos por Barragens, e etc. Após o fim da ditadura, um dos primeiros movimentos concretos de oposição à chamada "Revolução Verde" foi a luta pela Lei dos Agrotóxicos (ECOVIDA, 2007).

Neste contexto de busca e construção de novos conhecimentos em oposição ao estilo de agricultura da modernização conservadora, um dos movimentos contra hegemônicos surgidos foi o da Agroecologia, como um misto de novo enfoque científico e movimento social (BUTTEL, 1993) que se propõe a dar suporte para uma transição de agriculturas conservadoras para agriculturas sustentáveis.

Visto por este ângulo, a agroecologia pode ser entendida como uma reação às consequências negativas da aplicação das teorias modernizadoras, especialmente nos países mais pobres. Ela tem, por isso, um forte componente social, pois, pela sua proposição de redução de insumos externos e de preservação das condições naturais de produção, ela pode atuar de uma forma economicamente estabilizadora para agricultores familiares, objetivando a redução da dependência tecnológica (WOLFF, 1992).

O objetivo da agroecologia, segundo Gliessmann (2001), é o desenvolvimento de uma agricultura que seja, ao mesmo tempo, ambientalmente sustentável, produtiva e rentável. A particularidade social da agroecologia reside no fato de estar baseada na ação coletiva de determinados grupos na sociedade civil com referência na sua relação com a natureza. A agroecologia não ignora o conhecimento dos agricultores e valoriza, especialmente, a preservação dos recursos naturais, a geração de crescimento econômico sem destruição da natureza, fatores estes que, juntamente com o trabalho, constituem a base histórica da produção agrícola.

A agroecologia propõem-se, assim, a um processo de aprendizagem, na medida em que os agricultores devem ser capacitados a refletir organizadamente sobre seus problemas concretos e, acompanhados de conhecimentos científicos, a desenvolver soluções que, tendo em vista a sua complexidade, exigem uma ampla organização social e política, de forma que o capital cultural (conhecimento) possa se converter em capital social e econômico, no sentido de Bourdieu (1983).

No entanto, conceituar a Agroecologia é uma tarefa complexa, um conceito que não pode ser fechado e sim ter uma base conceitual em evolução, de acordo com a sua própria filosofia. Levando em consideração alguns princípios de base, a agroecologia e a agricultura familiar interagem entre si, formando uma amálgama 
onde se completam. Por exemplo, os princípios adotados no discurso do grupo estudado giram em torno de: policultivos e produção de autoconsumo; manutenção da cobertura vegetal; rotação de culturas e consórcio de plantas; implantação de sistemas agroflorestais (SAF's); preservação de recursos naturais; integração da produção animal e vegetal; valorização do conhecimento tradicional, que foi passado através de gerações; cooperação em rede entre agricultores, técnicos, organizações de representação, movimentos populares e consumidores (VIANEI, 2009).

Diante disto, o discurso da agroecologia pode ser tomado como uma forma de resistência ao modo de produção convencional capitalista, tendo como argumento a democratização do uso dos recursos naturais, o respeito ao meio ambiente e às pessoas, além da ideia de horizontalidade.

O feminismo, ou as questões de gênero, por sua vez, tem sido utilizado como um discurso e uma prática que contribui neste cenário de resistência e transformação da agricultura, destacando-se a luta contra a violência sobre as mulheres, a valorização do seu trabalho e seu protagonismo nos processos de produção agroecológica. Há experiências em que a produção agroecológica e a participação crescente em espaços políticos têm contribuído para o empoderamento das mulheres, para que as mesmas transponham o espaço doméstico, obtendo mais independência e autoestima.

O processo de construção da identidade política "mulher agricultora" no paradoxo das lutas de gênero remete ao fato de que muitas delas passam a ocupar cargos estratégicos nas associações e sindicatos nos quais as famílias, bem como suas unidades produtivas, estão inseridas. Estas condições contribuem para a alteração das relações de gênero, através da distribuição do trabalho doméstico entre os demais membros da família (pai e filhos), por exemplo, e a inclusão da mulher no planejamento produtivo da propriedade, recentemente com o respaldo de políticas públicas.

As práticas sociais de distinção, como o discurso de "desenvolvimento sustentável" no campo através de conhecimentos e experiências fundamentadas na agroecologia, colocam-se também em meio a uma busca por mudanças sociais e políticas - equidade e inclusão social, respeito à natureza, solidariedade - entre as quais, as questões/relações de gênero, tem sido colocadas como importantes e merecedoras de debate.

Para Karam (2004), é fundamental conhecer e desvendar o papel da mulher no processo de ruralidades:

No campo da produção ela tem sido precursora dentro da unidade familiar, assumindo os desafios de começar algo novo, ao mesmo tempo que desafia a produção convencional ao pôr em prática saberes adquiridos com outras gerações. Muitas vezes é ela quem reintroduz sementes há muito guardadas nas próprias hortas domésticas, testa formas e preparados no cultivo, recupera a cooperação em todas as esferas da produção. É ela que tem garantido a sociabilidade no mundo rural, atuando no espaço privado - na família, na vizinhança, na religiosidade. Ela silenciosamente faz as articulações e 'costuras' do tecido social da unidade familiar, da família extensa e da comunidade.

A sociedade considera produtivo tudo aquilo que gera riqueza e que, geralmente, aparece como sendo exercido pelos homens. Já o trabalho reprodutivo é aquele realizado pelas mulheres no cuidado da casa, comida, marido e filhos (MEDEIROS, 2010). No entanto, a percepção do papel da mulher tem pautado cada 
vez mais as relações de gênero e, consequentemente, tem-se destacado nos discursos idealizados pelas lutas de classe. Isto firma-se com a luta que as próprias mulheres fazem em prol da sua emancipação, para que a sociedade como um todo, principalmente o meio rural, as vejam como precursoras de mudanças importantes e quiçá históricas.

Vale ressaltar que dinâmicas de empoderamento do gênero feminino, pautada pela resistência de sua ruralidade, representa também um mecanismo de resistência ao movimento da masculização do campo, cuja progressão pode ser verificada em estatísticas oficiais, no âmbito nacional e internacional. ${ }^{6}$

\section{METODOLOGIA}

Através de consulta a entidades públicas e pesquisadores que trabalham com assistência técnica, extensão rural e agroecologia na região, foram elencados alguns grupos de agricultores(as), dentre os quais se escolheu um que apresenta características marcantes em relação à resistência e persistência da ruralidade na região do Planalto Sul de Santa Catarina. Anteriormente ao primeiro contato com o grupo escolhido, realizou-se uma revisão bibliográfica a fim de analisar e criar hipóteses sobre o estudo de caso a realizar-se; indo de encontro com as questões denominadas ruralidade, agroecologia e gênero.

O universo de pesquisa para a produção deste artigo foi a Associação das Famílias Agricultoras de Otacílio Costa - AFAOC que desenvolvem atividades neste município situado no Planalto Sul de Santa Catarina. A AFAOC existe a quatorze anos e é formada predominantemente por mulheres. O desafio em permanecer na propriedade levou as mulheres a buscar alternativas para o sustento familiar e através da agroecologia pretendiam aumentar a sua renda, autonomia, acesso à informações, oportunidade de capacitação e segurança alimentar das famílias. Este grupo de agricultoras têm sido pressionadas a abandonarem suas atividades rurais, face a um cenário de expansão gradativa de reflorestamento de pinus (Pinus sp).

Para a realização do estudo, utilizou-se a abordagem teórico-metodológica de Pierre Bourdieu, através dos conceitos de habitus, capitais e de reprodução social (BOURDIEU, 1989). Estes conceitos, conhecidos da sociologia, devem ser tratados no conjunto das formulações teóricas que os contém. Todavia, de modo esquemático, e dentro dos limites e objetivos deste trabalho, adotou-se o conceito de habitus como um sistema de disposições duráveis que orienta as ações e percepções que os indivíduos adquirem ao longo das suas experiências. Trata-se de uma matriz, determinada pela posição social do indivíduo, que lhe permite pensar, ver e agir nas mais variadas situações. O habitus traduz ou expõe, no decorrer da ação, estilos de vida, julgamentos políticos, morais, estéticos. Conforme Setton (2002) pode ser visto também como uma noção que auxilia o indivíduo a pensar as características de uma identidade social, de uma experiência biográfica, um sistema de orientação ora consciente ora inconsciente. Funciona como uma matriz cultural que predispõe os indivíduos a fazerem suas escolhas, inclusive na construção das identidades sociais. Embora individual, o habitus é resultado de uma pré-disposição social, vem associado aos capitais e a posição ocupada num determinado campo social. Pode ser visto também, em termos mais genéricos, como um modo de ser ou de fazer na vida social, seguindo uma regularidade de acordo com o conjunto dos capitais do indivíduo no campo.

\footnotetext{
${ }^{6} \mathrm{Tal}$ aspecto, ainda que relevante, não será aprofundado no presente trabalho. Para aprofundamento ler Dos Anjos, Caldas e Pollnow (2014).
} 
Para Bourdieu, o capital está relacionado ao poder, ou aos recursos que um agente pode mobilizar na disputa do poder num campo. Temos o capital social (relações sociais, prestígio) e o capital cultural (conhecimentos reconhecidos, títulos, diplomas, bens culturais), que constituem o capital simbólico, e o capital econômico (rendas, bens materiais) que, frequentemente associados, constituem as formas de obtenção ou reprodução do poder e da dominação social (ou como no caso em estudo, formas de obter recursos de resistência social). O capital social está relacionado as redes de relações sociais, as quais permitem aos indivíduos ter acesso aos recursos dos membros do grupo ou da rede, e também a quantidade e a qualidade de recursos do grupo. O volume de capital social de um agente individual depende tanto da extensão da rede de relações que ele pode efetivamente mobilizar como do volume das diferentes formas de capital (econômico, cultural ou simbólico). É esta participação que lhes permite apropriar-se dos benefícios materiais e simbólicos que circulam entre os membros da rede. E essa apropriação possibilita a reprodução do capital social pelo grupo, e assim a reprodução social do grupo, conferindo-lhe identidade e uma maior objetivação simbólica (ou seja, fazer com que a sua representação simbólica seja vista pelos outros de um modo objetivo).

Estes conceitos brevemente esboçados serão operacionalizados da seguinte forma: $O$ conceito de habitus será avaliado pelas representações e pelo modo com o se inserem na sociedade. As representações que as agricultoras fazem delas mesmas e que os outros fazem delas. Elas incorporaram o habitus de "mulheres agricultoras agroecológicas", protetoras da natureza, etc. Assim, o habitus emerge de um esforço de objetivação: elas se tornam aquilo que "os outros esperam que elas sejam", que por sua vez é resultado do discurso que elas fazem sobre si mesmas e, portanto, as levam a agir de acordo. No caso do grupo em questão, agir de acordo com o discurso da agroecologia, realizar feiras, participar de eventos, reuniões, socializações, moldando-se conforme os acontecimentos.

O capital social e cultural podem ser avaliados pelo conjunto de conhecimentos, aquilo que foi acumulado pelo conhecimento, apropriação de discursos, produtos, espaços a serem ocupados, tudo aquilo que contribui para a distinção do habitus e que objetive a representação de mulheres ecológicas. Para tal, precisam plantar, precisam vender na feira, viajar, participar de eventos, e assim se distinguem e acumulam capital social. Elas aumentam seu capital social estando ligadas a uma rede de agroecologia, realizaram vários cursos e produzem alimentos que são ecológicas "na prática", não só no discurso.

A acumulação do capital simbólico pôde ser avaliado através de indicadores da identidade sociocultural, da politização na qual o grupo se envolve, da liderança e da noção de gênero. Enquanto o processo de acumulação do capital econômico pôde ser avaliado através das práticas agroecológicas, do valor diferenciado dos produtos, do acesso às políticas públicas e nichos de mercado. A partir desses conceitos, identificou-se os mecanismos de distinção e práticas de reprodução social da ruralidade.

O estudo configurou-se diante desta comunidade identificada como resistente ao processo de perda da ruralidade, constatada como recorrente na região. Para a coleta de dados foram realizados estudos de investigação que captassem as práticas e representações sociais das agricultoras, através de perguntas orientadas no sentido de compreender as estratégias utilizadas pelo grupo, com base numa abordagem qualitativa. Contou-se também com a observação participante durante reuniões e com impressões através de visitas às propriedades, às feiras, diálogos individuais e registros fotográficos. Procurou-se compreender sociologicamente como a cultura e o comportamento caracterizam o grupo estudado. 


\section{MULHERES AGRICULTORAS AGROECOLÓGICAS: O CASO DE OTACÍLIO COSTA - SC}

A Associação das Famílias Agricultoras de Otacílio Costa - AFAOC existe desde o ano 2000 e é formada predominantemente por mulheres. A criação da associação é justificada como sendo um desafio em permanecer na propriedade, o que teria levado as mulheres a buscar alternativas para o sustento familiar, aumentando a sua renda através da agroecologia, tendo mais autonomia, acesso a informações, oportunidade de capacitação e segurança alimentar das famílias.

Os agricultores de Otacílio Costa têm sido pressionados a abandonar suas atividades rurais devido a expansão gradativa de reflorestamento de pinus por empresas reflorestadoras e proprietários rurais independentes. Há aproximadamente 40 anos, na região em torno do atual município de Otacílio Costa, teve início a implantação de extensos reflorestamentos com pinus, em substituição ao uso da araucária na fabricação de papel e celulose. O crescimento desta indústria e a ampliação dos reflorestamentos com a correspondente compra generalizada de terras, marcou a vida dos habitantes da região (FERT NETO, 1993). Com o surgimento e expansão do reflorestamento, os agricultores passaram a receber propostas de compra de suas terras por valores que pareciam altos o suficiente para comprar uma casa na cidade. As agricultoras da AFAOC relatam que suas infâncias são relembradas em meio à decomposição do ambiente em que viviam, através da derrubada da mata nativa e do aparecimento de maquinários, pessoas e atividades nunca antes vistos.

Desta forma, ao longo dos anos, o reflorestamento comercial tomou conta da área rural do município, rodeando e pressionando as poucas famílias que não venderam tudo que possuíam. As famílias que venderam suas terras, posteriormente, acabaram morando no meio urbano e trabalhando nas mesmas empresas de reflorestamento que compraram suas terras. As agricultoras do grupo relatam ainda que, até recentemente, recebem propostas insistentes de compra de suas propriedades, no entanto não é o desejo destas famílias seguirem o rumo das demais. Devido a issoprocuram maneiras de resistir no meio rural.

A constituição da associação e da sua identidade teve origem a partir de práticas sociais e religiosas praticadas pelo grupo. As mulheres se conheceram na igreja e através da Pastoral da Saúde obtiveram conhecimento sobre uma Organização Não Governamental que tinha como proposta o trabalho em agroecologia e educação popular. A criação da associação decorreu da participação em cursos e o contato direto com os ideais da agroecologia, o que as fez formar uma consciência de rejeição à agricultura convencional, adotando uma postura de defesa da família e do meio ambiente. Segundo uma das agricultoras entrevistadas:

A associação é fruto dos cursos no Centro Vianei e da nossa boa vontade, a gente fazia remédios naturais porque senão a família ia pro hospital por causa dos agrotóxicos, nossos parentes antigamente plantavam sem veneno, então colocamos na cabeça que a gente ia achar uma maneira de fazer o mesmo.

Desta forma, a agroecologia surge como uma forma de resgate de um processo de vida tido pelos seus ancestrais, não só relacionado a aspectos produtivos, mas abordando hábitos cotidianos e culturais herdados. A reconstituição de tais práticas iniciou-se mais especificamente com os conhecimentos existentes 
acerca de plantas medicinais, trabalho que vinha sendo realizado há muitos anos, mesmo antes de existir a associação. Junto desses conhecimentos tradicionais já adquiridos e emancipados, conforme dito por uma das agricultoras, começou a busca por mais pessoas dispostas a envolver-se na causa da AFAOC.

O primeiro passo foi dado por três mulheres que procuraram motivar outras famílias a participar de encontros após as missas da comunidade, onde havia doação de alguns remédios e pomadas caseiros. Este processo despertou elementos do passado rural de outras mulheres, que se interessaram pela causa e passaram a participar do grupo, como relata uma das agricultoras fundadoras da associação: "a mulherada andava desanimada, plantavam uma vez por ano, os maridos trabalhando fora (...) mas acreditamos, buscamos e o amor pela natureza nos identificou, começamos em quatro famílias". A partir disso, encontros periódicos eram realizados a fim de traçar metas e objetivos para a associação, que embora politicamente estivesse se afirmando através da participação de movimentos sociais e do campo, precisava concretizar diretrizes para suas atividades produtivas, envolvendo desde as práticas culturais até os meios de comercialização.

Constatou-se que a unidade de produção familiar típica camponesa já não existia como tal, na medida em que os homens saiam para trabalhar como empregados em empresas de reflorestamento e as mulheres ficavam em casa sem desenvolver trabalho produtivo/comercial, e nem ao menos tinham essa perspectiva. Eventualmente, cultivavam algumas espécies, limitando-se à milho e feijão. Segundo uma agricultora do grupo, não havia o conhecimento entre as mulheres de que era possível cultivar nas quatro estações do ano.

Com a associação formada e um número maior de mulheres engajadas, firmou-se o propósito de realizar feiras semanais, com o intuito de vender os alimentos diretamente ao consumidor. Tal propósito configurou-se como estratégia para fazê-las produzir alimentos, além de estabelecer um compromisso entre a associação com consumidores e com sua própria identidade, contribuindo,consequentemente, para a renda da família.

A associação conquistou um espaço para realização da feira no centro da cidade, representando o principal mecanismo de comercialização dos alimentos produzidos pelas famílias ${ }^{7}$. A feira vem sendo reconhecida aos poucos e, lentamente, a cidade adquire o status de "Otacílio Sustentável", o que vem de encontro ao trabalho realizado pela associação. Vale ressaltar que tal estatus também é promovido no município pelas empresas de reflorestamento, como apelo ambientalista, procurando evidenciar o equilíbrio entre a prática produtiva/econômica e a conservação do ambiente.

Através dos relatos das agricultoras e de visita a feira constatou-se que os produtos vegetais ofertados na feira são olerícolas, algumas ofertadas frequentemente como alface, rúcula,brócolis, repolho, cenoura temperos in natura, enquanto outras são ofertadas de acordo com a sazonalidade do produto, como tomate, batata e cebola. Segundo as agricultoras, no primeiro semestre de cada ano também é possível comercializar grãos, principalmente milho e feijão, assim como ervilhas. Produtos de origem animal são evitados em função de restrições impostas pela vigilância sanitária. Além de produtos de origem vegetal, são ofertados também panificados processados artesanalmente, como pães, biscoitos e bolos. Não existe uma escala entre as agricultoras quanto aos produtos que cada uma oferta na feira. Em geral, todas levam os mesmos produtos, muitas vezes em quantidades

\footnotetext{
${ }^{7}$ Ressalta-se que outras formas de comercialização dão-se através de programas como PAA (Programa de Aquisição de Alimentos) e PNAE (Programa Nacional de Alimentação Escolar), através dos quais se dá a entrega de alimentos para hospitais, creches, escolas e APAE.
} 
diferentes, mas sem distinção quanto ao produto ofertado. O lucro efetivo oriundo das vendas foi sutilmente velado pelas entrevistadas, contudo todas enfatizaram o significado deste lucro como um componente a mais na composição da renda familiar de cada uma.

No que diz respeito à certificação dos alimentos agroecológicos produzidos pela AFAOC, possuem o sistema de certificação participativa da Rede Ecovida há mais de 10 anos. Neste sistema, a elaboração e a verificação das normas de produção ecológica são realizadas com a participação efetiva de agricultores e agricultoras, técnicos e consumidores, buscando o aperfeiçoamento constante e o respeito às características e a cultura de cada realidade.

Com técnicas agrícolas utilizadas no processo produtivo, nota-se que houve o cuidado em resgatar o conhecimento tradicional, àquele criado e transformado mediante experiências ao longo de muitas décadas. Conforme relato de uma das agricultoras: "Uma coisa linda que tem na agroecologia e que não podemos deixar morrer é que se uma coisa deu certo pra você, você tem que passar pro outro". Desta forma, a troca de experiências configura-se como a principal forma de obtenção de tecnologias para o meio produtivo, unindo conhecimentos tradicionais advindos dos antepassados e as técnicas de cunho agroecológico altamente difundidas na atualidade, através do aprendizado em cursos e participação em eventos e espaços de sociabilidades rurais onde toda e qualquer forma de conhecimento é levada em conta e entendida como importante para o desenvolvimento de uma agricultura sustentável e justa.

O controle de doenças e insetos nos cultivos, mesmo por meios naturais, é evitado ao máximo e recorrido somente em últimos casos. As mulheres creem no pressuposto de que ao ter-se uma planta bem nutrida, não haverá problemas no seu desenvolvimento (teoria da trofobiose), o que remete ao fato de manejarem a nutrição do solo e da planta com rigor, usando, por exemplo, ureia natural (urina de vaca em lactação) como adubo foliar.

A troca de sementes é considerada um ponto importantíssimo e forte dentro da AFAOC. Po fazer parte da Rede Ecovida de Agroecologia, a qual congrega vários grupos agroecológicos do sul do Brasil, a AFAOC está inserida numa rede que preserva uma significativa diversidade de sementes crioulas, passadas de geração a geração, cultivadas e trocadas entre as famílias para que não se percam. Isso proporciona às mulheres da associação o reconhecimento de seu status de guardiãs de sementes, como relata uma das agricultoras: "Mesmo as pessoas que não estão dentro da associação, eles valorizam a gente, sabem onde encontrar sementes que eles precisam, eles contam com a gente".

Ao longo do discurso das agricultoras, evidencia-se a preocupação com a dificuldade em contar com os indivíduos mais jovens da família, filhos e netos, para auxiliá-las nas atividades do campo. Percebeu-se uma expectativa de que, quando os filhos estabelecerem-se financeiramente, os mesmo irão retornar e seguir adiante o trabalho feito por elas até então. No entanto, se não houver ação concreta relativa aos jovens, essa persistência estará fadada ao desaparecimento.

A prática da associação alterou as relações de gênero, a mulher passou a ter outro papel, contribuindo para a renda da família e com certa independência. No entanto, para algumas agricultoras, a opção pela permanência rural ocorreu antes da associação e antes de incorporarem o discurso e práticas agroecológicas. Olhando retrospectivamente, a permanência no campo se constitui como justificativa e molde para a construção e participação da AFAOC. Nota-se tal aspecto no relato de uma das agricultoras: 
(...) eu fiquei 26 anos morando no sítio e o marido trabalhando na cidade, na empresa, criei minhas duas filhas assim, ele só vinha final de semana, sítio sempre comigo, eu não quis ir embora pra praça, poderia ter uma casa lá, uma boa casa, mas eu não quis, eu aqui plantava e economizava e ele lá trabalhava, conseguimos comprar, mesmo não tendo terra e morando no terreno do meu pai, 3 alqueires de terra, 7.2ha de terra, que isso não é herança, é comprado.

Atualmente, a associação é formada em sua maioria por mulheres, contando com a presença de dois homens, o que acaba por gerar alguns conflitos entre gêneros. Considerando que as mulheres prezam mais pela socialização e pela construção de uma identidade agroecológica, além do amor pela natureza, os homens - e algumas das mulheres - visam mais o aspecto econômico, usufruindo de um nicho de mercado.

Inicialmente houve muita resistência dos homens em relação a participação das esposas na associação e as atividades tanto produtivas como sociais com as quais elas começaram a se familiarizar e atuar desde então. Este cenário foi se modificando, embora de maneira lenta e difícil, conforme os resultados financeiros foram surgindo, como as agricultoras relataram-nos: "começaram a ver que desde uma panela nova, um jogo de cama, até um galão de tinta, a gente comprava pra dentro de casa com a renda da feira, minha filha fez faculdade com dinheirinho todo da feira".

A relação das agricultoras com a institucionalidade está pautada pela negação às politicas públicas de financiamento: "Uma das ideologias da AFAOC é não acessar o $\operatorname{PRONAF}^{8}$ (...) porque a gente tá vendo o tanto que a mulher vai ficar passando de mal pagadora, a gente não gosta disso, vamos gastar pra produzir o que temos, se não der, damos um jeito". Assim, de acordo com as agricultoras, embora haja interesse na assessoria e na assistência técnica oficial, não há grande vínculo entre a AFAOC e a entidade pública de extensão rural - EPAGRI (Empresa de Pesquisa Agropecuária e Extensão Rural de Santa Catarina).

Tal aspecto constrasta com a realidade estudada por Souza et al. (2016) no Estado do Pernambuco. Neste estudo, os autores observaram a direta influência da entidade oficial de extensão rural, o Instituto Agronômico de Pernambuco, na mobilização e organização de um grupo de agricultoras (Associação Municipal Mulher Flor do Campo), bem como no desencadeamento de arranjos produtivos. No que tange as políticas de crédito, Souza et al. (2016) afirmam que o acesso às linhas de crédito do PRONAF pelas agricultoras contribuíram para incrementar a produção e a renda em suas unidades produtivas, sem comprometer seus orçamentos familiares.

Observou-se também a negação em relação ao mercado formal de produtos, apresentando em seus discursos a prática de venda direta ao consumidor, sem atravessadores. No entanto, acessam os programas de comercialização PAA (Programa de Aquisição de Alimentos) e PNAE (Programa Nacional de Alimentação Escolar) por serem programas congruentes com a ideologia de fornecer alimentos saudáveis à população e instituições.

Essa vigilância ao sistema institucionalizado, assistência técnica oficial, programa de crédito e mercado formal, constitui-se como uma forma de distinção, não se deixando serem absorvidas e cooptadas. Afirmam e concretizam: "É pequena nossa história, mas nós mesmas estamos fazendo".

\footnotetext{
${ }^{8}$ Programa Nacional de Fortalecimento a Agricultura Familiar.
} 


\section{DISCUSSÃO: CONSTRUÇÃO DA IDENTIDADE E A PERSISTÊNCIA DA RURALIDADE}

A partir da trajetória das mulheres da AFAOC, pode-se estabelecer algumas análises sobre o processo de construção de identidade e a consequente estratégia de persistência da ruralidade. Esta, demonstrou ser resultado de intervenções externas e de uma mobilização dos próprios rurícolas, e compreendem:

- Recuperação de conhecimentos tradicionais, numa perspectiva agroecológica, através de orientação técnica da ação extensionista prestada por uma ONG com viés agroecológico. Esta estratégia compreendeu técnicas de baixo uso de insumos, sem endividamentos bancários, num contexto de diminuição progressiva da agricultura familiar e da produção local, dada à expansão das plantações de pinus e o aumento do emprego exclusivamente urbano e masculino;

- Agregação das agricultoras em uma associação e seu vínculo a uma rede ecológica proporcionou a inserção em mercados de preços diferenciados, uma feira de produtos agroecológicos que ocorre todas as semanas na praça municipal. Esta feira possui uma identidade própria de agroecológica e é reconhecida pela comunidade, que a frequenta e interage socialmente no ambiente da feira. A feira permite agregação de renda aos produtos, em sua maioria hortaliças, mas também alimentos de processamento artesanal e eventuais artesanatos. A feira permite também uma renda extra, fortalecendo a autonomia feminina no processo de permanência da ruralidade. Num determinado sentido, pode se falar de uma contratendência à masculinização do campo, embora numericamente limitada ao grupo em questão.

As práticas culturais e a reinvenção do conhecimento tradicional proporcionaram uma identidade sociocultural de "agricultoras agroecológicas". Essa identidade permite uma distinção e acumulação de capital simbólico (BOURDIEU, 1989) que se converte em capital econômico na medida em que pode sensibilizar o consumo consciente ou solidário dos moradores do município, muitos deles tendo perdido recentemente sua condição material de rurícola, mas com um imaginário ainda de camponês. O aumento do capital simbólico aumenta a capacidade de liderança e politização, potencializando os processos de organização, comunicação e agência frente às estratégias e políticas públicas.

Identificou-se que a busca por renda não foi o principal motivador destas mulheres, mas sim a defesa da família, saúde, convivência e criação de um espaço social próprio. No entanto, estes valores sociais e simbólicos também resultaram em pequeno capital econômico, mas que possibilitou uma grande autonomia, dada a condição anterior de mulheres de agricultores para mulheres agricultoras.

Assim, reconhece-se que aspectos econômicos e sociais têm um papel decisivo no processo de resistência à perda progressiva da ruralidade e na inviabilização da agricultura familiar. Isto ocorre de um modo ainda mais acentuado numa região onde predominam a produção de pinus e concentração de terras. Não obstante, estratégias como as observadas no grupo estudado permitem inferir que alternativas produtivas como as práticas agroecológicas aliadas ao associativismo e à identidade social, inclusive de gênero, podem viabilizar a ruralidade desses grupos. Estas estratégias permitiram criar uma identidade de grupo, caracterizandoo e, desta forma, favorecendo a resistência do rural e da autenticidade camponesa.

Há uma congruência entre os aspectos simbólicos e materiais no processo de reprodução da ruralidade. Assim, as estratégias de desenvolvimento rural, principalmente aquelas dos próprios rurícolas, bem como as políticas públicas, no caso a extensão rural agroecológica, devem atentar não somente para a produção e 
as técnicas produtivas, mas também para as condições sociológicas e simbólicas em que se realizam as ações, incluindo as condições de gênero. Esta, muitas vezes considerada como um obstáculo ao desenvolvimento, neste caso, verificou-se como sendo um recurso simbólico construído pelas próprias protagonistas.

\section{CONCLUSÃO}

Conclui-se que a manutenção econômica deste grupo depende de um processo de acumulação de capital simbólico, conforme o conceito de Bourdieu, e esse capital se dá de diferentes maneiras: pode ser explicado através de uma identidade sociocultural, mulheres agricultoras agroecológicas, ou seja, elas se identificam como tal, e portanto adquirem o capital simbólico do que é distinto. Um processo que depende da política e não da economia e nem da questão individual. Começam a ter entendimentos de como funciona a política, os processos sociais, são lideranças dentro da comunidade e particularmente neste caso, possuem a noção de gênero e de valorização das mulheres.

Uma análise sociológica acurada sobre formas de persistência da ruralidade poderia contribuir para orientar políticas públicas levando em conta o processo social de grupos específicos. Isto permitiria considerar os processos de desenvolvimento social com base nas experiências e expectativas dos próprios atores envolvidos (LONG; VAN DER PLOEG, 1994).

Muitas políticas públicas têm procurado equacionar o problema do baixo desenvolvimento socioeconômico em áreas rurais que sofreram forte êxodo rural, como é o caso do Planalto Sul Catarinense, que possui um baixo IDH, tanto urbano quanto rural. Nem sempre essas políticas têm obtido sucesso, principalmente aquelas que procuram inserir os camponeses num sistema mercantil, que no capitalismo atual é altamente competitivo e excludente.

As políticas públicas existentes, embora devam estar voltadas para crédito, tecnologias e acesso a mercado, podem não ser eficazes muitas vezes ao aspecto social. Se tal aspecto fosse atingido, poderia fortalecer outras estratégias, ou seja, o agricultor passaria a se valorizar e ser visto como tal e não como alguém marginalizado, em decadência ou atrasado.

Entretanto, identificou-se como algo problemático para a análise a falta de perspectiva na continuidade da reprodução social, visto que a próxima geração não está engajada nas atividades, o que remete a necessidade de políticas públicas para o envolvimento e permanência dos jovens no campo.

Desta forma, essas políticas poderiam focar no sentido de propiciar maior perspectiva de inclusão social e no fluxo de vida das pessoas do meio rural ou recém urbanizadas. Isto permitiria aperfeiçoar tanto as políticas públicas, como também respeitar os processos socioculturais das diferentes comunidades, empoderando os camponeses no seu próprio caminhar histórico.

\section{REFERÊNCIAS}

ABRAMOVAY, R. Agricultura familiar e desenvolvimento territorial. Reforma agrária, v. 28, n. 1, p. 2, 1998.

BLOEMER, N. M. S. Brava gente brasileira: migrantes italianos e caboclos nos campos de Lages. Florianópolis: Cidade Futura, 2000.

BOURDIEU, P. Questões de sociologia. Rio de Janeiro: Marco Zero, 1983. 
BOURDIEU, P. O poder simbólico. Lisboa: Ed. DIFEL, 1989.

BUTTEL, F. The Production of Agricultural Sustainability: Observations from the Sociology of Science and technology in: ALLEN, P. Food for the future. New York: John Wiley \& Sons, 1993.

CAPORAL, F. R.; COSTABEBER, J. A. Agroecologia: alguns conceitos e princípios. Brasília, 2004.

ANJOS, F. S.; CALDAS, N. V.; POLLNOW, G. E. Menos mulheres, menos jovens, mais incertezas. A transição demográfica no Brasil Rural Meridional. Extensão Rural, v. 21, n. 2, p. 94-116, 2014. Disponível em:

$<$ https://periodicos.ufsm.br/extensaorural/article/view/10453>. Acesso em 20 de out. 2016.

DURÁN, F. E. Viejas y nuevas imágenes sociales de ruralidad. Estudos Sociedade e Agricultura, n. 11, p. 76-98, 1998.

ECOVIDA, Rede de Agroecologia. Uma identidade que se constrói em rede:

Caderno de Formação 01. Lapa/PR, 2007.

FERT NETO, J. O clientelismo nas relações de trabalho capitalistas. Dissertação de Mestrado. Programa de Pós-Graduação em Sociologia. Universidade Federal do Rio Grande do Sul.Porto Alegre: UFRGS, 1993.

GLIESSMAN, S. R. Agroecologia: processos ecológicos em agricultura sustentável. Porto Alegre: UFRGS, 2001.

GOULARTI FILHO, A. Formação econômica de Santa Catarina. Florianópolis: Cidade Futura, 2002.

GRAZIANO DA SILVA, J. Progresso técnico e relações de trabalho na agricultura. São Paulo: Hucitec, 1981.

GRAZIANO DA SILVA, J.; GROSSI, M. D.; CAMPANHOLA, C. O que há de realmente novo no rural brasileiro. Cadernos de Ciências \& Tecnologia, v. 19, n. 1, p. 37-67, 2002.

HAESBAERT, R. Da desterritorialização a multiterritorialização. In: Anais do X Encontro de Geógrafos da América Latina. São Paulo, 2005.

KARAM, K. F. A agricultura orgânica como estratégia de novas ruralidades: um estudo de caso na Região Metropolitana de Curitiba. In: V Encontro da Sociedade Brasileira de Sistemas de Produção e V Simpósio latinoamericano sobre investigação e extensão em sistemas agropecuários. Florianópolis, 2002.

KARAM, K. F. A mulher na agricultura orgânica e em novas ruralidades. Revista Estudos Feministas, v. 12, n. 1, p. 303-320, 2004.

LEFEBVRE, H. Perspectivas da sociologia rural. In: MARTINS, J. de S. (Org.). Introdução crítica à sociologia rural. São Paulo: Hucitec, 1986. 
LONG, N.; VAN DER PLOEG, J.D. Heterogeneity, Actor and Structure: toward a reconstitution of the concept of structure. In: Booth, D. (ed.), Rethinking social development. London: Longman, 1994.

MARTINE, G. et al. Impactos sociais da mModernização agrícola. São Paulo: Caetés, 1985.

MEDEIROS, R. O combate à violência a partir da auto-organização das mulheres e da agroecologia. Mulheres e agroecologia: sistematizações de experiências de mulheres agricultoras, v. 1, Rio de Janeiro/RJ, 2010.

SANTA CATARINA, Secretaria de Estado de Planejamento, Orçamento e Gestão, Secretaria de Estado de Desenvolvimento Regional. Lages - caracterização Regional: estudo elaborado pelo Instituto Cepa/SC, para a Secretaria de Estado do Planejamento, Orçamento e Gestão. Florianópolis, 2003.

SETTON, M. G. J. A teoria do habitus em Pierre Bourdieu: uma leitura contemporânea. Revista Brasileira de Educação, n. 20, p. 60-70, 2002.

SOUSA, G. M. B. et al. A extensão rural e a perspectiva de gênero na agricultura familiar: a atuação do IPA junto à Associação Municipal Mulher Flor do Campo.

Extensão Rural, Santa Maria, v. 23, n. 2, p. 46-59, 2016. Disponível em:

$<$ https://periodicos.ufsm.br/extensaorural/article/view/16985>. Acesso em 22 out. 2016

VIANEI, Centro de Educação Popular. Rede de agroecologia do território do Planalto Catarinense. Lages/SC, 2009.

WANDERLEY, M. N. B. A emergência de uma nova ruralidade nas sociedades modernas avançadas: o rural como espaço singular e ator coletivo. Estudos Sociedades e Agricultura, n. 15, p. 87-146, 2000.

WILLIAMS, R. O campo e a cidade. São Paulo: Companhia das Letras, 1989.

WOLFF, L. A. Ecofarming im Spannungsfeld zwischen Technologie und Politik. Saarbrücken: Breitenbach, 1992. 